\title{
A contribuição das fontes de rendimento na dinâmica da distribuição espacial de renda no Brasil
}

Alexandre Gori Maia IE/UNICAMP

\section{Palauras-chave \\ disparidade regional, distribuição de renda, análise de dados espaciais, aposentadorias e pensões, teoria da convergência.}

Classificação JEL D63, O15, R12, J26, $\mathrm{J} 31$.

\section{Key words}

regional disparities, income distribution, spatial data analysis, pensions, convergence theory.

JEL Classification D63, O15, R12, J26, J31.

\section{Resumo}

Este trabalho analisa a dinâmica dos padrões espaciais de concentração de renda dos municípios brasileiros entre os anos de 1980 e 2000. Para avaliar as diferentes configurações que surgem dessa distribuição, analisa-se ainda o grau de dependência dos municípios em relação às diferentes fontes de rendimento (trabalho, aposentadorias, pensões e outras fontes) e sua contribuição para a dinâmica da desigualdade no território. De maneira geral, destaca-se o importante papel das diferenças regionais na extrema desigualdade de renda no Brasil e a relevante contribuição dos rendimentos não provenientes do trabalho, sobretudo aposentadorias e pensões, para a redução das diferenças entre as rendas per capita municipais.

\section{Abstract}

The main purpose of this paper is to analyze the dynamics of spatial inequality among Brazilian municipalities from 1980 to 2000. In order to evaluate the different patterns of income distribution, the paper also analyzes the municipalities' dependence level in relation to different sources of income (labor, pensions and other sources) and its contribution to the dynamics of income inequality in the territory. Overall, it intends to highlight the important role of regional disparities in the Brazilian income inequality and the relevant contribution of non-labor incomes, especially pensions, to reduce differences among municipalities per capita household income. 


\section{1_ Introdução}

Todos os estudos de distribuição de renda no Brasil constatam os elevados níveis de pobreza e desigualdade de sua população (Barros et al., 2000), o que estaria associado ao seu processo histórico de desenvolvimento socioeconômico (Furtado, 1986). Desde a colonização, o Brasil observa extrema concentração de terras em favor de um restrito número de proprietários, e, atualmente, essa desigualdade se reproduz de forma acentuada na distribuição de rendimentos da população (Hoffmann, 2001). Mesmo com a pronunciada redução das diferenças nos anos 2000 (Barros et al., 2007), o Brasil ainda se consolida como uma das nações mais desiguais do planeta. ${ }^{1}$

Entre os condicionantes do elevado grau de desigualdade socioeconômica, podem-se destacar aqueles derivados das diferenças regionais (Hall e Jones, 1996). Assim como os elementos históricos, culturais e ambientais influenciariam o grau de desenvolvimento socioeconômico de uma região, os diferentes estágios de desenvolvimento regional determinam distintas estruturas socioeconômicas, exercendo papel fundamental na distribuição geográfica da população e da renda (Maia, 2009).
Alguns estudos procuram captar, sobre diversos enfoques e dimensões de análise, tendências de convergência da renda entre as regiões brasileiras. Ferreira e Diniz (1995), por exemplo, identificam clara tendência à contínua convergência absoluta das rendas per capita estaduais entre os anos 1970 e 1985. Analisando o período de 1981 a 1996, Azzoni et al. (2000) descartam a hipótese de convergência absoluta, mas sugerem uma tendência de convergência das rendas estaduais condicionadas às características geográficas, de capital humano e infraestrutura dos Estados. Magalhães e Miranda (2008), por sua vez, analisam a diferença entre as rendas per capita municipais no período de 1970 a 2000 e sugerem um grave processo de divergência entre essas na época, embora identifiquem grupos de convergência regional, ou seja, regiões com tendência de redução da desigualdade entre seus municípios.

Para ajudar a compreender os padrões e a dinâmica da desigualdade no território brasileiro, este trabalho propõe-se a analisar a evolução da renda domiciliar per capita de grupos municipais nos anos 1980 a 2000. Tendo em vista as mudanças implementadas na Divisão Territorial Brasileira nos períodos inter-
De acordo com o Human Development Report, da Organização das Nações Unidas, de 2009, dos 142 países presentes no relatório com indicadores de desigualdade, o Brasil apresentava o $10^{\circ}$ pior índice de Gini (UNDP, 2009). 
censitários, os municípios foram agrupados em 3.659 Áreas Mínimas Comparáveis (AMCs) segundo metodologia proposta pelo Instituto Brasileiro de Geografia e Estatística (IBGE) e pelo Instituto de Pesquisa Econômica Aplicada (IPEA) (Rangel et al., 2007).

A análise das rendas dos grupos municipais ajudará a compreender os diferentes padrões socioeconômicos do território, sobretudo daqueles que se referem ao acesso a bens e serviços públicos e mercantis, diretamente associados à renda da população (Rocha, 2002). Para avaliar as diferentes composições que surgem da distribuição da renda, será ainda considerado o grau de dependência dos municípios em relação às diferentes fontes de rendimento (trabalho, aposentadorias, pensões e outras fontes), bem como sua associação à dinâmica da desigualdade no território.

As análises basear-se-ão nas diferenças entre os grupos de municípios e na relação espacial que surge dessa configuração, sem deixar de considerar a distribuição interna de seus habitantes. Compreender as relações no espaço é fundamental para, entre outros motivos, subsidiar o planejamento e as decisões quanto à localização das atividades econômicas produtivas, consumo privado e coletivo, bem como prover ferramentas para o conhecimento das relações sociais vigentes e dos padrões espaciais que delas emergem (IBGE, 2008b).

Combinando o emprego de medidas de desigualdade, técnicas de análise multivariada e de dados espaciais, pretende-se identificar as principais mudanças nos padrões e na dinâmica da distribuição de renda entre os municípios brasileiros e dentro deles. A hipótese principal dessa análise é que, embora permaneça um expressivo grau de concentração espacial, o rendimento não proveniente do trabalho, principalmente aposentadorias e pensões, cumpriu importante papel no crescimento da apropriação de renda domiciliar per capita dos grupos municipais mais pobres.

Para cumprir com os objetivos propostos, este trabalho está estruturado em três partes principais, além desta introdução e das considerações finais: i) breve contextualização da desigualdade no Brasil, entre os anos 1980 e 2000; ii) descrição da base de dados e dos métodos de análise; iii) apresentação e discussão dos resultados referentes a: a) dinâmica da distribuição espacial da renda domiciliar per capita e b) contribuição das diferentes fontes de rendimento. 


\section{2_Dinâmica da desigualdade no Brasil}

Os primeiros estudos sobre desigualdade no Brasil apontam para um acentuado processo de concentração da renda entre os anos 1960 e 1970. Para Fishlow (1972) e Hoffmann e Duarte (1972), um determinante fundamental dessa dinâmica seria a política de compressão salarial implantada no governo militar, que teria favorecido a desvinculação entre salários e crescimento do excedente nos setores mais dinâmicos da economia. Langoni (1973), por sua vez, atribui o crescimento da desigualdade à interação entre o rápido crescimento econômico e a baixa disponibilidade de mão de obra qualificada, que proporcionou melhores oportunidades e remunerações a uma pequena parcela de profissionais mais qualificados.

Após crescer substancialmente entre 1960 e 1976, a desigualdade caiu entre 1976 e 1979 e, a partir dos anos 80, passou por períodos de extrema volatilidade (Barros et al., 2007; Soares, 2006). Segundo Ferreira et al. (2006), a dinâmica da desigualdade entre 1981 e 2004 pode ser caracterizada por três momentos distintos: i) contínuo crescimento entre 1981 e 1989; ii) período de alta volatilidade e picos entre 1989 e 1993; iii) queda quase sucessiva entre 1993 e 2004, sobretudo a partir de 2001.

Para esse mesmo autor, os fatoreschave para o crescimento da desigualdade entre 1981 e 1993 seriam: i) a rápida expansão do nível de educação da força de trabalho, quando o efeito negativo da nova composição dos grupos educacionais sobrepôs-se ao impacto positivo do declínio dos retornos marginais da educação sobre a remuneração; ii) a elevada inflação do período, cujos impactos estariam diretamente associados ao nível de riqueza das famílias e seriam mais prejudiciais aos mais pobres. Por sua vez, a queda da desigualdade entre 1993 e 2004 estaria associada a três fatores principais: i) a redução dos retornos marginais da educação; ii) o significativo aumento no volume e grau de focalização das políticas de transferência do governo; iii) o processo de convergência entre as grandes regiões e sobretudo entre áreas urbanas e rurais.

A análise da composição dos rendimentos permite outras importantes considerações sobre os determinantes da desigualdade. Nas últimas décadas, por exemplo, caiu a participação da renda do trabalho na renda total e cresceu principalmente a participação do rendimento 
O Censo Demográfico é a mais importante pesquisa domiciliar do IBGE, aplicada decenalmente em praticamente todo o território nacional. São considerados todos os domicílios brasileiros, com exceção daqueles pertencentes a algumas raras tribos isoladas ao contato do homem branco (IBGE, 2002). de aposentadorias e pensões (Hoffmann, 2006; Soares, 2006). Para Hoffmann (2006), analisando o período de 1997 a 2004, o rendimento de aposentadorias e pensões agiria ainda regressivamente sobre a distribuição dos rendimentos domiciliares per capita, ou seja, contribuiria para aumentar a desigualdade total.

Esse mesmo autor também destaca o pequeno crescimento do rendimento oriundo de outras fontes sobre a renda total, mas seu substancial impacto na redução da desigualdade no período. Ainda que represente menos de $2 \%$ da renda total, o rendimento de outras fontes seria responsável por cerca de $1 / 4$ da redução do índice de Gini entre 1997 e 2004. Adicionalmente, a concentração dos benefícios dos programas de transferência de renda nas regiões mais pobres do $\mathrm{Pa}$ ís teria acentuado o papel do rendimento de outras fontes sobre a queda da desigualdade nessas localidades. No Nordeste, por exemplo, a participação do rendimento de outras fontes subiu de $0,6 \%$ para 3,3\% da renda total entre 1998 e 2004 e representou quase $50 \%$ da queda de seu índice de Gini nesse período (Hoffmann, 2006).

A partir de 1998, a desigualdade da distribuição do rendimento do trabalho também passou a cair, embora em ritmo menos acelerado que o do rendimento de outras fontes (Soares, 2006). Entretanto, por essa fonte representar parcela majoritária da renda total, acabou sendo responsável por aproximadamente $3 / 4$ da redução do índice de Gini no período.

De maneira geral, os resultados apresentados destacam a necessidade da consideração de alguns importantes condicionantes da dinâmica da desigualdade entre os anos 1980 e 2000. Entre esses: i) o período de extrema instabilidade política e econômica nos anos 80; ii) a política social do Estado, aumentando a abrangência e a magnitude dos benefícios sociais aos mais pobres (aposentadoria rural, Benefício de Prestação Continuada, Bolsa-Família, entre outros) nos anos 90; ii) a quase que contínua valorização do salário mínimo a partir de 1994 (Barros et al., 2007).

\section{3_Material e métodos}

As análises basearam-se em informações dos Censos Demográficos dos anos 1980, 1991 e 2000. ${ }^{2}$ Consideraram-se 3.659 AMCs, as quais levam em conta emancipações e mudanças nas divisas municipais realizadas entre 1980 e 2000 (Rangel et al., 2007). 
As informações sobre os rendimentos autodeclarados do Censo Demográfico permitiram desagregar a análise segundo três fontes principais: i) trabalho; ii) aposentadorias e pensões; iii) outras fontes. O primeiro refere-se tanto ao rendimento da ocupação principal quanto ao de outras ocupações que a pessoa possa exercer no período de referência. As rendas provenientes de aposentadorias ou pensões são aquelas pagas por instituto de previdência ou pelo governo para uma pessoa aposentada ou beneficiária. Já os rendimentos de outras fontes referem-se àqueles provenientes de aluguéis, programas de transferência de renda, pensão alimentícia, abono permanência ("pé na cova"), fundos privados de complementação do salário ou pensão, doações e mesadas, entre outros.

Todos esses rendimentos dizem respeito a valores brutos recebidos em dinheiro no mês de referência. ${ }^{3}$ Para pessoas com rendimentos variáveis, considera-se uma média, corrigida para o mês de referência, dos 12 meses anteriores à pesquisa (IBGE, 2002). Não são considerados rendimentos esporádicos como abonos salariais, parcelas do $13^{\circ}$ salário, adiantamento de férias, vendas eventuais de bens móveis e imóveis, ganhos ocasionais de jogos, entre outros.
Os valores foram deflacionados para reais $(\mathrm{R} \$)$ de $1^{\circ}$ de outubro de 2007 , a partir do INPC corrigido para o Censo Demográfico, ajuste feito no índice de inflação a fim de considerar as variações percebidas no dia $1^{\circ}$ de cada mês, período de referência para os rendimentos captados pelo Censo, e não no dia 15 como originalmente prevê sua metodologia (Corseuil e Foguel, 2002).

A análise da distribuição de renda da população com base em rendimentos autodeclarados exige algumas ressalvas importantes. A autodeclaração provoca uma subestimação nos rendimentos que varia de intensidade em função do tipo de rendimento analisado. Segundo (Barros et al., 2000), a subdeclaração na PNAD é maior, em primeiro lugar, para a renda do trabalho, em virtude da não consideração de rendimentos eventuais (décimo terceiro, férias, horas extras, participação nos lucros, entre outros) e benefícios não monetários (veículos, celulares, alimentos, entre outros). Posteriormente, a subdeclaração aparece para as rendas de ativos (aluguéis, juros, dividendos, entre outros) e rendas de transferências (indenizações trabalhistas, seguro desemprego, entre outros). De maneira geral, a subestimação ocorreria tanto para ricos quanto para pobres, sendo maior entre
Não é considerada a parcela do pagamento efetuada em benefícios, tais como: moradia, alimentação (refeições, cesta de alimentos, vale ou tíquete-alimentação), vale ou tíquete-transporte, roupas (IBGE, 2002). 
os mais pobres. Não haveria, entretanto, impactos substanciais sobre o grau de desigualdade medido pela PNAD (Barros et al., 2000).

As análises baseiam-se na diferença das rendas domiciliares per capita entre os indivíduos. Entre as AMCs, essas correspondem à diferença entre rendas per capita das localidades. Três métodos principais foram utilizados para analisar a distribuição dos rendimentos entre os municípios e dentro deles: i) medidas de desigualdade; ii) técnicas de análise de dados espaciais; iii) e análise de agrupamentos.

\section{Medidas de desigualdade}

A diferença entre as rendas per capita das AMCs foi analisada segundo algumas das principais medidas de desigualdade (Hoffmann, 1998): i) massa de renda apropriada pelas AMCs segundo décimos de renda per capita; ii) curva de Lorenz; iii) índice de Gini. O primeiro passo consiste em ordenar crescentemente as AMCs segundo a renda per capita. A distribuição das AMCs segundo décimos de renda per capita permite verificar como a população e a renda total se distribuem entre as AMCs relativamente mais pobres e mais ricas. Por sua vez, a curva de Lorenz re- presenta graficamente essa relação, com a proporção acumulada da renda total (ordenadas) variando em função da proporção acumulada da população total (abscissas). O índice de Gini $(0 \leq G<1)$ baseia-se nos resultados da curva de Lorenz e pode ser expresso por:

$\mathrm{G}=1-2 \beta$

Onde $\beta$ representa a área entre a curva de Lorenz e o eixo das abscissas.

O índice de Gini foi ainda decomposto para considerar o efeito de cada fonte de rendimento sobre a desigualdade entre as AMCs e sua dinâmica entre os anos 1980 e 2000. Para isso, considerou-se o Gini como uma soma ponderada das razões de concentração das três fontes $f$ de rendimento (Hoffmann, 2006):

$\mathrm{G}=\sum_{f=1}^{3} \mathrm{p}_{f} \mathrm{C}_{f}$

Onde $p_{f}$ é a participação da $f$-ésima fonte de rendimento na renda total, e $C_{f}$ sua respectiva razão de concentração, dada por:

$\mathrm{C}_{f}=1-2 \beta_{f}$

A razão de concentração de cada fonte $\left(-1<C_{f}<1\right)$ é obtida de maneira análoga ao índice de Gini, mas com base em uma curva de concentração individualiza- 
da para cada fonte $f$ de rendimento. Nesta, a proporção acumulada da renda total é substituída pela proporção acumulada da f-ésima fonte de rendimento, mantendo-se a hierarquização original das rendas per capita das AMCs. Assim, $\beta_{f}$ será a área entre a curva de concentração para a f-ésima fonte de rendimento e o eixo das abscissas.

Para avaliar a contribuição de cada fonte sobre a mudança do índice de Gini entre 1980 e $2000(\Delta G)$, considerouse a expressão (Hoffmann, 2006):

$$
\Delta \mathrm{G}=\sum_{f=1}^{3}\left[\left(\overline{\mathrm{C}}_{f}-\overline{\mathrm{G}}\right) \Delta \mathrm{p}_{f}+\overline{\mathrm{p}}_{f} \Delta \mathrm{C}_{f}\right]
$$

Onde $\bar{C}_{f}, \bar{G}$ e $\bar{p}_{f}$ representam os valores médios das respectivas medidas em 1980 e 2000 . O primeiro termo dentro do somatório representa o efeito composição e indica o quanto da variação do Gini se deve à mudança do peso de uma fonte de renda (Soares, 2006). O segundo termo, o efeito concentração, indica o quanto da variação se deve à mudança na concentração de uma fonte de renda.

Enquanto as medidas anteriores baseiam-se na diferença entre as rendas per capita das AMCs, o T de Theil foi utilizado para também considerar as diferenças entre indivíduos de uma mesma AMC. Seja uma população de tamanho $n$ e mas- sa de rendimentos igual a $Y$, em que cada indivíduo $i$ apropria-se de uma massa de rendimentos equivalente a $Y_{i}$, o cálculo do índice $T$ de Theil $(0 \leq T \leq \ln n)$ será dado pela expressão (Hoffmann, 1998):

Tde Theil $=\sum_{\mathrm{i}=1}^{\mathrm{n}} \frac{\mathrm{Y}_{\mathrm{i}}}{\mathrm{Y}} \ln n \frac{\mathrm{Y}_{\mathrm{i}}}{\mathrm{Y}}$

Valendo-se da propriedade de decomposição linear do $T$ de Theil, foi possível desagregar a desigualdade total em uma parcela devida à desigualdade interna às AMCs $\left(T_{\text {intra }}\right)$ e outra devida às diferenças entre essas $\left(T_{\text {entre }}\right)$. Genericamente, tem-se que:

$T$ de Theil $=T_{\text {entre }}+T_{\text {intra }}$

O princípio de desagregação do índice de Theil está na ponderação das contribuições parciais das rendas apropriadas por cada grupo de uma população e das desigualdades internas a esses. Seja $Y_{g}$ a massa da renda total apropriada pela $g$-ésima AMC e $n_{g}$ sua população total. A estimativa do índice $T$ de Theil para a desigualdade intra e entre as $k$ AMCs será dada por (Hoffmann, 1998):

$$
\begin{aligned}
& T_{\text {entre }}=\sum_{g=1}^{k} \frac{Y_{g}}{Y} \ln \frac{Y_{g} / Y}{n_{g} / n} \\
& T_{\text {intra }}=\sum_{g=1}^{k} \frac{Y_{g}}{Y} T_{g}
\end{aligned}
$$


${ }_{4}$ A rigor, o índice de Moran não está restrito ao intervalo de variação $(-1,1)$, embora, caso seja necessário, possa ser ajustado para forçar sua variação nesse intervalo teórico (Bailey e Gatrell, 1995).
Onde $T_{g}$ representa a desigualdade interna à g-ésima AMC e é obtido com base na expressão (1) considerando apenas a população dessa localidade.

\section{Índice Moran de autocorrelação espacial}

O índice Moran de autocorrelação espacial é uma medida estatística que permite avaliar o grau de dependência dos valores a partir de seus desvios em relação à média. Dado um atributo de interesse $X$ de uma população de $k$ elementos espaciais, o índice de Moran (I) será estimado por (Bailey e Gatrell, 1995):

$$
I=\frac{k \sum_{i=1}^{k} \sum_{j=1}^{k} w_{i j}\left(X_{i}-\bar{X}\right)\left(X_{i j}-\bar{X}\right)}{\left(\sum_{i=1}^{k}\left(X_{i}-\bar{X}\right)^{2}\right)\left(\sum \sum w_{i j}\right)}
$$

Onde $\bar{X}$ é a média de $X$, e $w_{i j}$ o elemento da matriz $(k \times k)$ de proximidade espacial $W$ que mensura a proximidade entre as áreas $A_{i}$ e $A_{j}$. Há vários critérios para cálculo de $w_{i j}$, sendo frequente a adoção de:

$$
\mathrm{w}_{\mathrm{ij}}\left\{\begin{array}{l}
1 \mathrm{se} \mathrm{A}_{\mathrm{i}} \text { e } \mathrm{A}_{\mathrm{j}} \text { são limítrofes } \\
0 \text { caso contrário }
\end{array}\right.
$$

O índice de Moran é frequentemente utilizado para medir o grau de as- sociação espacial de um atributo de interesse. Valores próximos a 1 indicam forte associação espacial positiva, ou seja, valores elevados de $X$ estariam espacialmente próximos a valores também elevados de $X$, sendo a recíproca válida para valores negativos. ${ }^{4}$

A estimativa do índice de Moran pode ser generalizada para considerar a autocorrelação de diferentes ordens espaciais. Uma vez conhecida $W^{(t)}$ a matriz de proximidade espacial de ordem $l$, o respectivo índice de Moran será dado por (Bailey e Gatrell, 1995):

$$
I^{(1)}=\frac{k \sum_{i=1}^{k} \sum_{j=1}^{k} w_{i j}^{(1)}\left(X_{i}-\bar{X}\right)\left(X_{j}-\bar{X}\right)}{\left(\sum_{i=1}^{k}\left(X_{i}-\bar{X}\right)^{2}\right)\left(\sum_{i \neq j} \sum w_{i j}^{(1)}\right)}
$$

Uma ordem superior a 1 significa que $A_{i}$ e $A_{j}$ não são limítrofes, já que há l-1 áreas entre eles. É comum a persistência de elevados índices para ordens baixas, uma vez que muitas variáveis tendem a apresentar forte relação com valores observados nas vizinhanças espaciais. A persistência de elevados índices mesmo para ordens mais avançadas sugere também a heterogeneidade espacial do atributo em questão, ou seja, a existência de fortes padrões de concentração espacial para os valores observados. 


\section{Análise de agrupamento}

Para identificar padrões relativamente homogêneos de dependência das AMCs em relação às fontes de rendimento, aplicou-se a análise de cluster, técnica estatística de análise multivariada que define grupos hierárquicos de observações de uma população. Há uma série de métodos que podem ser empregados nesse processo, mas todos se baseiam no mesmo princípio de agrupamentos hierárquicos. No início do processo, cada elemento da amostra representa um grupo. Os dois grupos mais próximos são unidos para formar outro, que os substitui, e assim sucessivamente, até que reste apenas um. A diferença entre os métodos está basicamente na maneira como a distância (ou dissimilaridade) entre os grupos é calculada (SAS, 1990).

O método de agrupamento adotado neste trabalho foi o de Ward, estratégia de agregação baseada na análise das variâncias dentro dos grupos formados e entre eles. O objetivo do método de Ward é criar grupos hierárquicos de tal forma que as variâncias dentro dos grupos sejam mínimas, e as variâncias entre os grupos, máximas (Crivisqui, 1999). Dada uma variável quantitativa $X$ de uma população com $n$ observações e $K$ grupos, em que o número de observa- ções do k-ésimo grupo será dado por $n_{k}$, a variabilidade total de $X$ pode ser decomposta em um componente dentro dos grupos e outro componente entre esses, como mostra a expressão (11):

Variabilidade total $=$ Variabilidade dentro + Variabilidade entre

$\sum_{\mathrm{i}=1}^{\mathrm{n}}\left(\overline{\mathrm{X}}_{\mathrm{i}}-\overline{\mathrm{X}}\right)^{2}=\sum_{\mathrm{k}=1}^{\mathrm{K}} \sum_{\mathrm{i}=1}^{\mathrm{n}_{\mathrm{k}}}\left(\mathrm{X}_{\mathrm{i}}-\overline{\mathrm{X}}_{\mathrm{k}}\right)^{2}+\sum_{\mathrm{k}=1}^{\mathrm{K}} \mathrm{n}_{\mathrm{k}}\left(\overline{\mathrm{X}}_{\mathrm{k}}-\overline{\mathrm{X}}\right)^{2}$

Onde $\bar{X}$ é a média de $X$, e $\bar{X}_{k}$ é a média do k-ésimo grupo.

Tais variabilidades podem também ser vistas como distâncias euclidianas do centro de gravidade (valor médio da população). Supondo agora o caso multivariado, com $P$ variáveis quantitativas, têm-se as seguintes medidas de distanciamento (SAS, 1990):

$$
\begin{aligned}
\sum_{\mathrm{i}=1}^{\mathrm{n}} \sum_{\mathrm{p}=1}^{\mathrm{p}}\left(\mathrm{X}_{\mathrm{ip}}-\overline{\mathrm{X}}_{\mathrm{p}}\right)^{2}= & \sum_{\mathrm{k}=1}^{\mathrm{K}} \sum_{\mathrm{i}=1}^{\mathrm{n}_{\mathrm{k}}} \sum_{\mathrm{p}=1}^{\mathrm{p}}\left(\mathrm{X}_{\mathrm{ip}}-\overline{\mathrm{X}}_{\mathrm{kp}}\right)^{2}+ \\
& +\sum_{\mathrm{k}=1}^{\mathrm{K}} \sum_{\mathrm{p}=1}^{\mathrm{p}} \mathrm{n}_{\mathrm{k}}\left(\overline{\mathrm{X}}_{\mathrm{kp}}-\overline{\mathrm{X}}_{\mathrm{p}}\right)^{2}
\end{aligned}
$$

Para evitar distorções procedentes das diferentes escalas de medidas das $P$ variáveis de análise, essas devem referir-se aos valores padronizados.

O critério de agregação de cada estágio consiste em encontrar a próxima classe que minimize a variabilidade dentro do novo grupo. No início do processo, tem-se um grau zero de generalização (todas as observações são distintas entre 
si) e ao final do processo temos $100 \%$ de generalização (todas as observações são semelhantes entre si). Deve-se decidir entre o número de grupos a definir na pesquisa, ou o grau de generalização que se pretende adotar, ou ainda uma interação entre as duas opções, analisando as perdas e os ganhos de cada escolha.

\section{Resultados e discussão}

\section{1_ Distribuição da renda total}

A conhecida desigualdade socioeconômica brasileira apresenta-se na distribuição da população e da renda de seus grupos municipais. No ano 2000, as 10\% AMCs mais ricas do País (366 de um total de 3.659), hierarquizadas segundo o valor da renda domiciliar per capita, apropriavam-se de $64 \%$ da renda total nacional, e a renda domiciliar per capita de sua população era oito vezes superior à das 10\% AMCs mais pobres (Tabela 1). Também chama a atenção a expressiva parcela de grupos municipais concentrada em uma baixa amplitude de rendimentos per capita, fruto do elevado grau de exclusão e desigualdade socioeconômica no Brasil. Por exemplo, a renda domiciliar per capita do oitavo décimo das AMCs era pouco superior a 400 reais mensais, valor $20 \%$ inferior à média nacional, e a parce- la de renda apropriada pelas $80 \%$ AMCs mais pobres não era superior a $1 / 4$ da renda total nacional.

As melhores oportunidades de renda e emprego atraem também o maior contingente populacional. Nas $10 \%$ das AMCs mais ricas, estavam $40 \%$ da população brasileira em 2000 (68 milhões dos 170 milhões de pessoas). A diferença entre distribuição de renda e população dos municípios brasileiros reflete a diferença dos rendimentos médios per capita, já que, caso a distribuição fosse semelhante, não haveria diferenças entre os rendimentos médios dos municípios. Assim, observa-se uma distribuição da população consideravelmente menos concentrada que a da renda. Por exemplo, as 40\% AMCs mais pobres concentravam $19 \%$ da população e apenas $6 \%$ da renda nacional em 2000.

Entre 1980 e 2000, a renda domiciliar per capita cresceu $20 \%$ e, de forma mais intensa, nos décimos mais pobres e intermediários de AMCs. Por exemplo, entre o $5^{\circ}$ e o $8^{\circ}$ décimos de AMCs, o crescimento foi igual ou superior a $26 \%$, contra $14 \%$ do décimo relativamente mais rico. No décimo mais pobre, o crescimento foi ainda mais expressivo $(42 \%)$, embora não suficiente para modificar o quadro de extrema exclusão des- 
Tabela 1_ Distribuição da população e da renda segundo décimos da renda "per capita" das AMCs - Brasil 1980, 1991 e 2000

\begin{tabular}{|c|c|c|c|c|c|c|c|c|c|}
\hline \multirow[b]{2}{*}{ Décimo } & \multicolumn{3}{|c|}{1980} & \multicolumn{3}{|c|}{1991} & \multicolumn{3}{|c|}{2000} \\
\hline & $\begin{array}{c}\text { População } \\
(\%)^{a}\end{array}$ & $\begin{array}{c}\text { Renda } \\
(\%)\end{array}$ & $\begin{array}{l}\text { Renda } \\
\text { "per capita" } \\
\text { (R\$) }\end{array}$ & $\begin{array}{c}\text { População } \\
(\%)^{a}\end{array}$ & $\begin{array}{c}\text { Renda } \\
(\%)\end{array}$ & $\begin{array}{l}\text { Renda } \\
\text { "per capita" } \\
\text { (R\$) }\end{array}$ & $\begin{array}{c}\text { População } \\
(\%)^{3}\end{array}$ & $\begin{array}{c}\text { Renda } \\
(\%)\end{array}$ & $\begin{array}{c}\text { Renda } \\
\text { "per capita" } \\
\text { (R\$) }\end{array}$ \\
\hline 1 & 4,0 & 0,7 & 70,5 & 3,7 & 0,7 & 74,0 & 3,8 & 0,8 & 100,0 \\
\hline 2 & 5,3 & 1,3 & 101,8 & 4,6 & 1,1 & 92,0 & 4,6 & 1,2 & 127,7 \\
\hline 3 & 5,9 & 1,8 & 126,5 & 5,4 & 1,5 & 109,4 & 5,0 & 1,5 & 149,5 \\
\hline 4 & 6,2 & 2,3 & 154,1 & 5,8 & 2,0 & 133,2 & 6,0 & 2,2 & 185,4 \\
\hline 5 & 5,3 & 2,4 & 188,7 & 5,2 & 2,2 & 166,1 & 5,5 & 2,6 & 240,7 \\
\hline 6 & 5,3 & 2,9 & 226,4 & 5,1 & 2,7 & 202,8 & 5,3 & 3,2 & 301,7 \\
\hline 7 & 6,6 & 4,3 & 273,9 & 7,2 & 4,6 & 247,9 & 8,0 & 5,7 & 358,3 \\
\hline 8 & 8,6 & 6,6 & 320,2 & 8,8 & 6,6 & 288,1 & 9,1 & 7,3 & 402,4 \\
\hline 9 & 14,3 & 13,3 & 390,1 & 14,8 & 13,6 & 354,8 & 12,6 & 12,0 & 475,5 \\
\hline 10 & 38,5 & 64,5 & 701,0 & 39,4 & 64,9 & 635,4 & 40,1 & 63,5 & 794,7 \\
\hline Total & 100,0 & 100,0 & 418,7 & 100,0 & 100,0 & 385,5 & 100,0 & 100,0 & 501,2 \\
\hline
\end{tabular}

Fonte: Elaboração do autor a partir dos microdados do Censo Demográfico 1980, 1991 e 2000/IBGE.

Obs.: Valores dos rendimentos em outubro de 2007 (INPC corrigido para o Censo Demográfico - IPEA)

se grupo de municípios, que apresentava renda domiciliar per capita média equivalente a apenas 59 reais mensais em 2000.

Duas considerações importantes devem ser feitas em relação à dinâmica dos rendimentos per capita nesse período. Em primeiro lugar, o relevante papel das mudanças observadas na composição das famílias, como redução de seu tamanho médio e maior participação feminina no mercado de trabalho, sobre o crescimento da renda per capita (Leone et al., 2009). Em segundo lugar, embora refli- ta tendência geral no período, a adoção desses três anos censitários leva a considerar uma importante variação da renda nesse período, o qual foi marcado por severas instabilidades políticas e econômicas (Carneiro, 2002).

Após uma série de tentativas frustradas de controle da inflação, o Plano Real, de 1994 trouxe estabilidade à economia e viabilizou, em um primeiro momento, a recuperação do poder de compra dos salários e, posteriormente, a implementação de políticas sociais que contri- 
Entre o $1^{\circ}$ e o $8^{\circ}$ décimo de grupos municipais, o crescimento da renda per capita foi igual ou superior a $42 \%$, contra uma média nacional de $34 \%$. buiriam para o País entrar em uma trajetória quase contínua de redução da desigualdade de renda (Neri, 2006). Para se comparar, entre 1980 e 1991, o Produto Interno Bruto real brasileiro cresceu apenas 1,5\% a.a., enquanto a inflação cresceu 439\% a.a. (IPEADATA, 2008). Diante desse quadro pouco favorável, nesse período a renda domiciliar per capita caiu $11 \%$ e, de maneira mais intensa, nos décimos intermediários da distribuição de rendimentos. Por outro lado, entre 1991 e 2000, houve recuperação da renda domiciliar per capita, sobretudo nos décimos mais pobres e intermediários, nos quais o crescimento foi bem superior à média nacional. ${ }^{5}$

No período como um todo, a dinâmica da renda e população fez crescer ligeiramente a contribuição dos municípios de alguns grupos decílicos intermediários. Por exemplo, aumentou em três pontos percentuais a apropriação de renda e em dois pontos percentuais a concentração populacional entre o $5^{\circ}$ e o $8^{\circ}$ grupos decílicos, sugerindo a maior importância das cidades médias e grandes no cenário socioeconômico nacional. Por outro lado, caiu principalmente a parcela da renda apropriada pelos décimos mais ricos da distribuição de rendimentos: dois pontos percentuais entre 1980 e 2000.
O Gráfico 1 complementa a análise com a curva de Lorenz para a relação entre as funções acumuladas de renda e população das AMCs. Constata-se evidente domínio da curva de 2000 em relação às de 1980 e 1991. Em outras palavras, o ano 2000 seria o mais igualitário no que se refere à distribuição das rendas entre as AMCs, sobretudo em função das diferenças observadas nos centésimos intermediários da distribuição. As curvas de 1991 e 1980 são muito semelhantes, e, embora a concentração em 1991 seja ligeiramente superior nos centésimos superiores, é mais igualitária nos centésimos intermediários das AMCs. De maneira geral, o índice de Gini calculado para a diferença entre as rendas per capita das AMCs sugere uma redução de 8,5\% na desigualdade entre 1980 e 2000 e de 1,5\% entre 1980 e 1991.

Para considerar a dinâmica da desigualdade entre as AMCs e dentro delas, calculou-se o índice $T$ de Theil para as rendas domiciliares per capita. Ainda que não tenha havido mudanças significativas na desigualdade entre as AMCs no período de 1980 a 1991, a maior recuperação da renda domiciliar per capita nos grupos intermediários entre 1991 e $2000 \mathrm{fez}$ a desigualdade entre as AMCs diminuir sensivelmente pelo $T$ de Theil 
Gráfico 1_Percentual acumulado da população e renda total das AMCs, hierarquizados segundo renda domiciliar "per capita" - Brasil 1980, 1991 e 2000

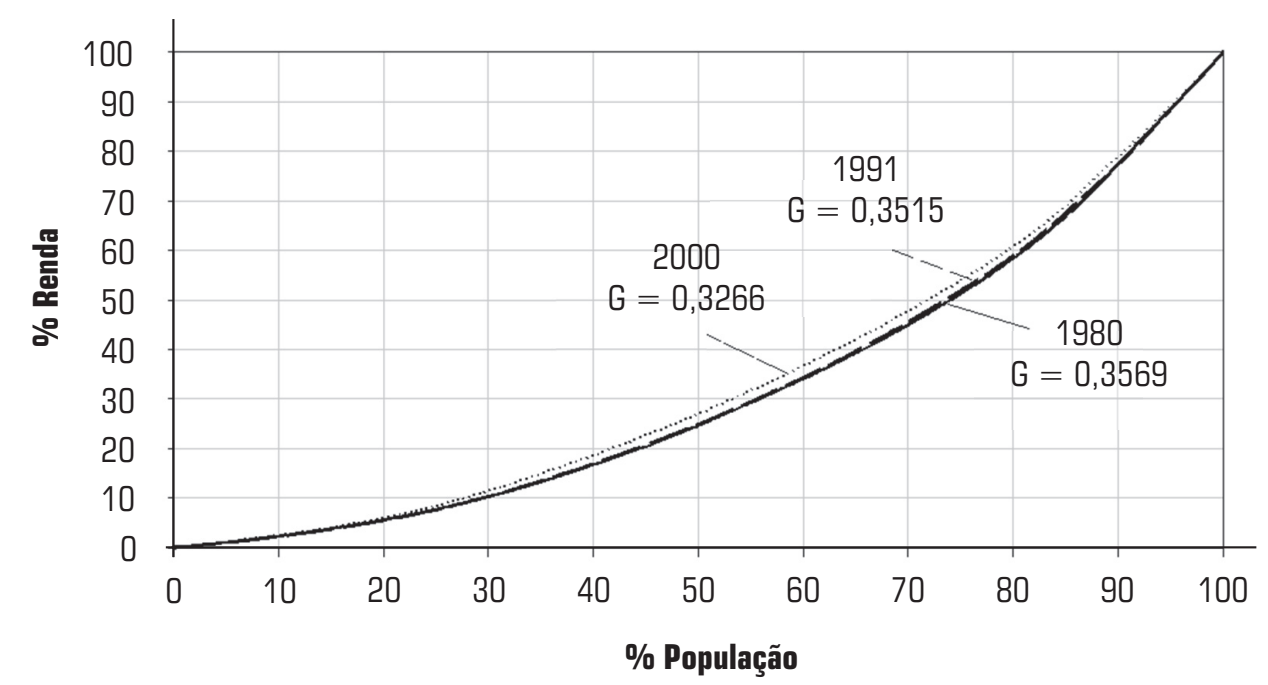

Fonte: Elaboração do autor a partir dos microdados do Censo Demográfico 1980, 1991 e 2000/IBGE.

(Tabela 2). $\mathrm{O}$ índice $T$ de Theil para a desigualdade das rendas per capita entre as AMCs brasileiras permaneceu praticamente estável entre 1980 e 1991, mas diminuiu 18\% entre 1991 e 2000 . Por outro lado, a desigualdade intrarregional cresceu substancialmente entre 1980 e 2000 (26\%), fazendo com que a desigualdade, no conjunto total da população, aumentasse $15 \%$ nesse período.

Tabela 2 _ Theil T para renda domiciliar "per capita" - Brasil 1980, 1991 e 2000

\begin{tabular}{c|c|c|c|c|c|c}
\multirow{2}{*}{ Ano } & \multicolumn{2}{|c|}{ Intra-AmCs } & \multicolumn{2}{c}{ Entre AmCs } & \multicolumn{2}{c}{ Total } \\
\cline { 2 - 7 } & Theil & $\%$ & Theil & $\%$ & Theil & $\%$ \\
\hline 1980 & 0,5621 & 74,5 & 0,1923 & 25,5 & 0,7544 & 100,0 \\
\hline 1991 & 0,6319 & 76,4 & 0,1954 & 23,6 & 0,8273 & 100,0 \\
\hline 2000 & 0,7098 & 81,7 & 0,1595 & 18,3 & 0,8693 & 100,0 \\
$\ldots$
\end{tabular}

Fonte: Elaboração do autor a partir dos microdados do Censo Demográfico 1980, 1991 e 2000/IBGE. 


\footnotetext{
${ }^{6}$ O salário mínimo nominal em outubro de 2000, 151 reais, correspondia a 255 reais quando corrigido para outubro de 2007 pelo INPC. A partir de múltiplos de 50 reais, valor próximo a um quinto desse valor, definiram-se seis faixas de renda per capita: i) até 100 reais; ii) entre 100 e 150 reais; iii) entre 150 e 200 reais; iv) entre 200 e 300 reais; v) entre 300 e 400 reais; vi) acima de 400 reais. Entre 1980 e 2000, esses valores discriminavam, aproximada e respectivamente, as $25 \%$ menores rendas per capita, próximas 25\%,15\%, 20\%, $10 \% \mathrm{e}$ $5 \%$ das maiores rendas per capita.
}

Deve-se ainda destacar a relevante contribuição das diferenças entre as AMCs para a desigualdade total, indicando a importância das diferenças regionais na consideração da extrema desigualdade brasileira. A parcela da desigualdade em razão da discrepância entre as AMCs oscilou entre $18 \%$ e $26 \%$ no período e significa, por exemplo, que, em 2000, a disparidade observada entre as 3.659 AMCs representava quase um quinto da desigualdade total verificada para os quase 170 milhões de brasileiros.

Para ajudar a compreender a dinâmica espacial dessas diferenças regionais, a Figura 1 apresenta a distribuição das AMCs segundo faixas de renda domiciliar per capita em mapas coropléticos, a forma mais comum e intuitiva de análise espacial de áreas. Definiram-se seis intervalos normativos de renda, com limites próximos a frações do salário mínimo vigente em 2000 e que, ao mesmo tempo, discriminam parcelas diferenciadas dos municípios e sugerem diferentes padrões de pobreza e riqueza relativa do território. ${ }^{6}$

As áreas mais contíguas de AMCs relativamente ricas aparecem nos Estados de São Paulo e do Rio de Janeiro, no Sudoeste de Minas Gerais, na região Sul e na área de expansão do agronegócio na região Centro-Oeste, seguindo um aparente prolongamento da dinâmica de desenvolvimento observada no Oeste Paulista (Maia, 2009).

Observam-se ainda poucas mudanças nos padrões espaciais de concentração de renda no período de análise. Assim como a redução da renda domiciliar per capita entre 1980 e 1991 se dera sobretudo nas bordas das áreas contíguas de riqueza relativa do território, o crescimento da renda domiciliar per capita dos grupos municipais observado entre 1991 e 2000 também ocorrera próximo às regiões mais ricas do País. Mantiveram-se, assim, os elevados padrões de concentração espacial da riqueza no País.

Outra maneira de analisar o grau de concentração espacial da renda é pelo índice de autocorrelação espacial. Os elevados índices de Moran para a renda per capita em todo o período de análise sugerem forte relação de dependência positiva entre as rendas de áreas vizinhas (Gráfico 1). Isso significa que municípios com elevados rendimentos per capita tendem a localizar-se próximos a municípios com rendimentos semelhantes. A persistência de altos índices para ordens mais elevadas, ou seja, para municípios mais distantes entre si, sugere ainda a heterogeneidade da distribuição de ren- 
Figura 1_ Distribuição espacial das AMCs segundo renda domiciliar "per capita" - Brasil 1980, 1991 e 2000
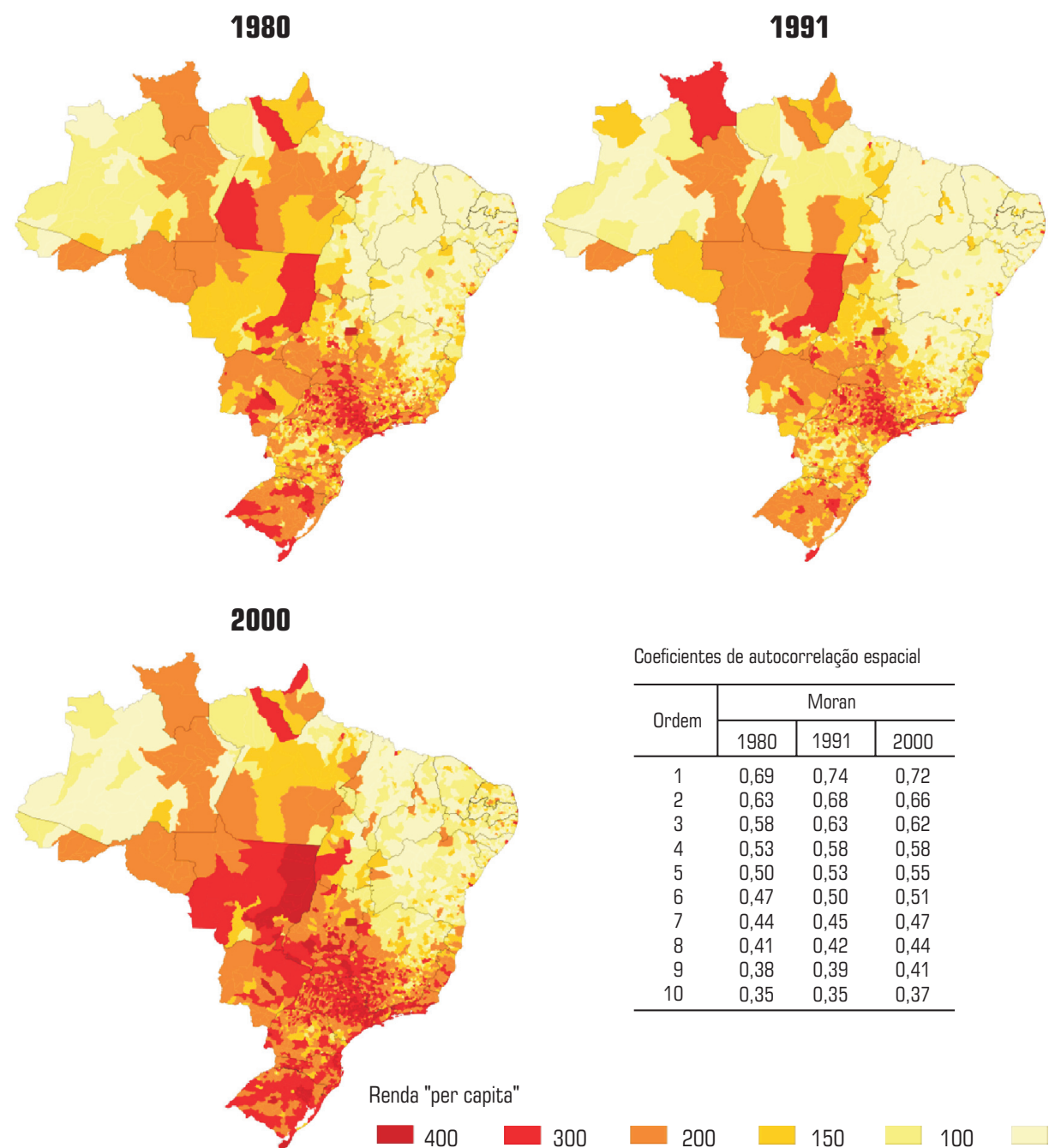

Coeficientes de autocorrelação espacial

\begin{tabular}{c|c|c|c}
\hline \multirow{2}{*}{ Ordem } & \multicolumn{3}{|c}{ Moran } \\
\cline { 2 - 4 } & 1980 & 1991 & 2000 \\
\hline 1 & 0,69 & 0,74 & 0,72 \\
2 & 0,63 & 0,68 & 0,66 \\
3 & 0,58 & 0,63 & 0,62 \\
4 & 0,53 & 0,58 & 0,58 \\
5 & 0,50 & 0,53 & 0,55 \\
6 & 0,47 & 0,50 & 0,51 \\
7 & 0,44 & 0,45 & 0,47 \\
8 & 0,41 & 0,42 & 0,44 \\
9 & 0,38 & 0,39 & 0,41 \\
10 & 0,35 & 0,35 & 0,37 \\
\hline
\end{tabular}

Fonte: Elaboração do autor a partir dos microdados do Censo Demográfico 1980, 1991 e 2000/IBGE.

Obs.: Valores dos rendimentos em outubro de 2007 (INPC corrigido para o Censo Demográfico - IPEA).

Elaborado com Philcarto. Disponível em: <http//philgeo.club.fr $>$. 
Entre 1980 e 2000 , houve crescimento da renda per capita de $15 \%$ na região Norte, $31 \%$ no Nordeste e apenas 14\% no Sudeste. da entre as regiões, com prevalência de fortes padrões espaciais no território. É o que se observa, por exemplo, na clara concentração de grupos municipais relativamente pobres nas extensas áreas do sertão nordestino e da floresta amazônica, e em grupos municipais relativamente ricos no Sul e no Sudeste do País.

O ligeiro crescimento do índice de Moran entre 1980 e 2000, mesmo para as ordens mais elevadas (AMCs mais distantes entre si), pode ainda sugerir pequena redução das disparidades espaciais. De fato, nesse período, a renda domiciliar per capita cresceu principalmente nas regiões Centro-Oeste (38\%) e Sul $(36 \%)$, aproximando-as da região Sudeste, a mais desenvolvida economicamente. Mesmo nas regiões menos desenvolvidas, Norte e Nordeste, o crescimento foi superior ao da região Sudeste. ${ }^{7}$ Comportamento análogo teria ocorrido em relação às AMCs intermediárias e grandes de localidades próximas, reduzindo as diferenças entre essas e, consequentemente, aumentando a relação entre suas rendas per capita.

Um dos problemas dos mapas coropléticos é que esses se limitam a apresentar a distribuição do espaço, não necessariamente da população, o que pode gerar distorção na análise da distribuição espacial (Bailey e Gatrell, 1995). Assim, embora alguns poucos grupos municipais concentrem boa parcela da renda e da população brasileira, especialmente próxima aos Estados de São Paulo e do Rio de Janeiro, as extensas áreas pouco povoadas de grupos municipais das regiões Centro-Oeste e Norte tendem a dominar a aparência do mapa, dando a falsa impressão de que suas características predominam no País.

Para contornar esse problema, elaboraram-se mapas de círculos proporcionais (Théry e Mello, 2008), com gradação de cores representando a distribuição das AMCs segundo faixas de renda domiciliar per capita e círculos proporcionais às suas respectivas rendas totais (Figura 2). As rendas superiores a 2 bilhões de reais mensais foram representadas por círculos vazios para facilitar a visualização. Manteve-se a proporcionalidade para todo o período de análise, ou seja, os círculos são proporcionais ao menor e maior valores observados no período de 1980 a 2000 .

As AMCs que contêm os municípios do Rio de Janeiro e, principalmente, de São Paulo, destacam-se na geração e apropriação da renda nacional. A AMC de São Paulo apropriava-se, sozinha, de $13 \%$ da renda total em 2000, Rio de Ja- 
Figura 2_ Distribuição espacial das AMCs segundo círculos proporcionais à renda total - Brasil 1980, 1991 e 2000

1980

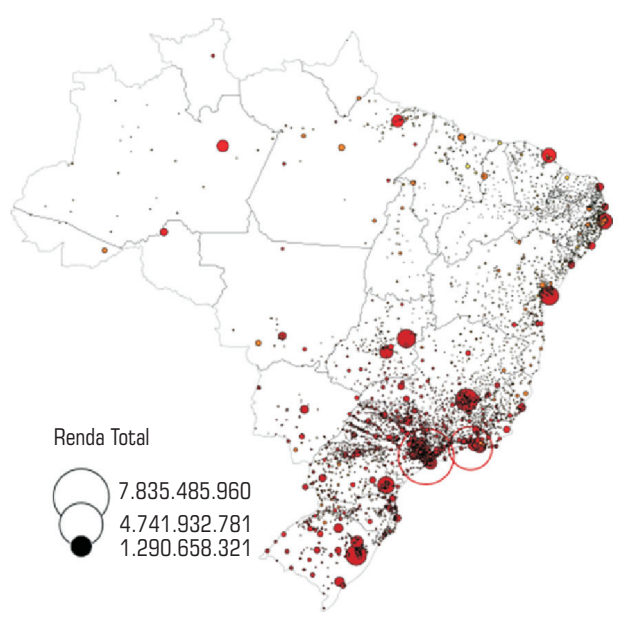

2000

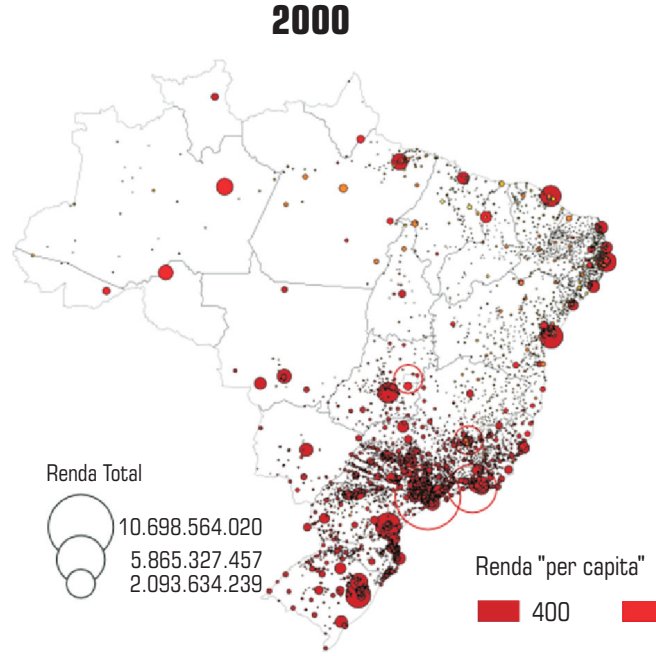

1991

Renda Total

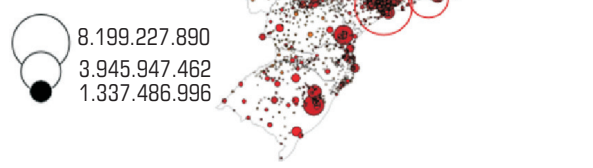

Fonte: Elaboração do autor a partir dos microdados do Censo Demográfico 1980, 1991 e 2000/IBGE.

Obs.: Valores dos rendimentos em outubro de 2007 (INPC corrigido para o Censo Demográfico - IPEA).

Elaborado com Philcarto. Disponível em: <http//philgeo.club.fr $>$. 
neiro de 7\%, e, a partir de Belo Horizonte, com a terceira maior apropriação de renda, essa percentagem passa a ser igual ou inferior a $2 \%$. Observa-se ainda uma importante área de concentração de renda no eixo que parte da capital paulista em direção ao Noroeste desse Estado, além de pontos praticamente isolados de concentração nas demais capitais estaduais e no Distrito Federal. Os grupos municipais relativamente mais pobres, por sua vez, são expressivos no espaço, mas inexpressivos na apropriação de renda e praticamente desaparecem no mapa de círculos proporcionais.

Entre 1980 e 2000, a apropriação de renda caiu principalmente nas AMCs das duas maiores e mais ricas cidades, São Paulo e Rio de Janeiro, com redução de três pontos percentuais em cada uma delas. Por outro lado, cresceu mais significativamente em AMCs de outras importantes capitais, como Brasília, Curitiba e Goiânia. Não houve, entretanto, mudanças significativas no quadro de extrema concentração da renda nacional. Mesmo em ritmo menos intenso, as AMCs das três capitais mais ricas, São Paulo, Rio de Janeiro e Belo Horizonte, continuam apropriando-se de parcela expressiva da renda total nacional $(22 \%$ em 2000, contra $28 \%$ em 1980). Belo Horizonte, to- davia, está prestes a perder a posição na concentração de renda para Brasília, caso permaneçam as tendências observadas no período.

\section{2_ Distribuição das fontes de rendimento}

A relevância de cada fonte de rendimento na composição da renda domiciliar per capita pode ser observada na Tabela 3. Ainda que o trabalho continue a ser a fonte majoritária de rendimento da população brasileira (78\% em 2000), houve expressiva redução de sua participação entre 1980 e 2000. Cresceu, por outro lado, a participação do rendimento de aposentadorias e pensões, que passou a representar 16\% da renda total em 2000.

Enquanto na década de 1980 o pequeno crescimento de 1,5 pontos percentuais na participação do rendimento de aposentadorias e pensões se deveu à redução da renda per capita do trabalho, na década de 1990 foi devido, basicamente, ao substancial crescimento do rendimento de aposentadorias e pensões. Este mais do que dobrou em termos per capita e aumentou em seis pontos percentuais sua participação na renda total. Dois fatores ajudam a explicar essa notável dinâmica: o envelhecimento da população e as mudanças implantadas no regime de previdência no Brasil. 
Tabela 3_Distribuição da renda segundo fontes de rendimento - Brasil 1980, 1991 e 2000

\begin{tabular}{l|c|c|c|c|c|c}
\multirow{2}{*}{ Fonte } & \multicolumn{2}{|c|}{$\mathbf{1 9 8 0}$} & \multicolumn{2}{c|}{$\mathbf{1 9 9 1}$} & \multicolumn{2}{c}{$\mathbf{2 0 0 0}$} \\
\cline { 2 - 7 } & $\begin{array}{c}\text { Renda } \\
\text { "per capita" }\end{array}$ & $\mathbf{\%}$ & $\begin{array}{c}\text { Renda } \\
\text { "per capita" }\end{array}$ & $\mathbf{\%}$ & $\begin{array}{c}\text { Renda } \\
\text { "per capita" }\end{array}$ & $\%$ \\
\hline Todos os trabalhos & 350,9 & 83,8 & 328,9 & 85,3 & 390,5 & 77,9 \\
\hline Aposentadorias e pensões & 36,2 & 8,7 & 39,3 & 10,2 & 79,3 & 15,8 \\
\hline Outras fontes & 31,6 & 7,5 & 17,3 & 4,5 & 31,3 & 6,2 \\
\hline Total & 418,7 & 100,0 & 385,5 & 100,0 & 501,2 & 100,0 \\
\hline
\end{tabular}

Fonte: Elaboração do autor a partir dos microdados do Censo Demográfico 1980, 1991 e 2000/IBGE. Obs.: Valores em outubro de 2007 (INPC corrigido para o Censo Demográfico - IPEA)

O envelhecimento da população brasileira está associado à transição demográfica observada nas últimas décadas, com acentuada queda da fecundidade, mortalidade e aumento da esperança de vida (Arriagada, 2006). O percentual de idosos com 60 anos de idade ou mais no Brasil, por exemplo, passou de 6\% em 1980 para 8\% em 2000 (IBGE, 2008a).

Mas a contribuição mais relevante para a expansão dos benefícios na população deveu-se às mudanças implementadas na Constituição de 1988 para o regime de previdência social. Entre as alterações, destacam-se: a vinculação do piso de benefício ao salário mínimo, o direito à aposentadoria ao trabalhador rural sem contribuição previdenciária e o benefício de prestação continuada, destinado aos idosos com renda familiar per capita inferior a meio salário mínimo. Es- sas alterações começaram a ser postas em prática a partir de 1991, estabelecendo uma cobertura universal nessa mesma década (Oliveira et al., 2008). Além de a parcela de beneficiários ter aumentado, a valorização quase contínua do salário mínimo a partir de 1994 contribuiu para a ampliação do rendimento de aposentadorias e pensões na renda total brasileira. $^{8}$

Tais mudanças também afetaram significativamente a distribuição dos rendimentos entre os grupos municipais brasileiros. Aumentou a parcela do rendimento de aposentadorias e pensões apropriada pelas AMCs relativamente mais pobres e caiu entre as relativamente mais ricas. Por exemplo, entre 1980 e 2000, a parcela do rendimento de aposentadorias e pensões apropriada pelos $40 \%$ das AMCs mais pobres subiu de 6\% para
Entre julho de 1991 e julho de 2000, o salário mínimo real valorizou 82\% (IPEA, 2008). 
Como pode ser observado com base nas informações da Tabela 1, a dinâmica da participação na população e no rendimento de aposentadorias e pensões apresentou comportamento divergente entre as AMCs relativamente pobres e ricas. Entre as primeiras, caiu a participação da população e aumentou a participação do rendimento de aposentadorias e pensões. Entre as relativamente ricas, aumentou a participação da população e caiu a participação do rendimento de aposentadorias e pensões.
$8 \%$ e caiu de $69 \%$ para $65 \%$ nas $10 \%$ das AMCs mais ricas (Tabela 4), mesmo com a tendência oposta para suas respectivas populações. ' Em outras palavras, a extensão dos benefícios às populações mais pobres reduzira a participação relativa daquelas mais ricas de tal forma que, em 2000, o rendimento de aposentadorias e pensões já apresentava a distribuição menos desigual das três fontes de rendimentos entre os grupos municipais brasileiros.
Redução ainda mais intensa ocorreu para a desigualdade na distribuição do rendimento proveniente de outras fontes. Embora ainda represente o caso mais extremo de concentração entre as fontes analisadas, caiu de 79\% para 71\% a parcela desse tipo de rendimento apropriada pelos $10 \%$ das AMCs mais ricas e subiu de $2 \%$ para $5 \%$ a parcela apropriada pelas $40 \%$ das AMCs mais pobres. Essas mudanças estariam associadas à expansão dos programas direcionados de

Tabela 4 _ Distribuição de renda segundo décimos da reda domiciliar "per capita" das AMCs e fonte de rendimento - Brasil 1980, 1991 e 2000

\begin{tabular}{|c|c|c|c|c|c|c|c|c|c|}
\hline \multirow[b]{2}{*}{ Décimo } & \multicolumn{3}{|c|}{1980} & \multicolumn{3}{|c|}{1991} & \multicolumn{3}{|c|}{2000} \\
\hline & Trab. & $\begin{array}{c}\text { Apos. } \\
\text { Pensão }\end{array}$ & Outros & Trab. & $\begin{array}{c}\text { Apos. } \\
\text { Pensão }\end{array}$ & Outros & Trab. & $\begin{array}{c}\text { Apos. } \\
\text { Pensão }\end{array}$ & Outros \\
\hline 1 & 0,7 & 1,1 & 0,2 & 0,8 & 1,1 & 0,5 & 0,6 & 1,3 & 0,7 \\
\hline 2 & 1,3 & 1,5 & 0,4 & 1,2 & 1,4 & 0,8 & 0,9 & 1,8 & 1,0 \\
\hline 3 & 2,0 & 1,8 & 0,6 & 1,6 & 1,8 & 1,0 & 1,4 & 2,3 & 1,3 \\
\hline 4 & 2,4 & 1,9 & 0,9 & 2,1 & 2,2 & 1,3 & 2,1 & 2,8 & 1,8 \\
\hline 5 & 2,8 & 2,2 & 1,2 & 2,5 & 2,3 & 1,8 & 2,6 & 2,7 & 2,2 \\
\hline 6 & 3,3 & 2,2 & 1,6 & 2,8 & 2,0 & 2,1 & 2,9 & 2,8 & 2,5 \\
\hline 7 & 4,7 & 3,4 & 2,7 & 4,3 & 3,8 & 3,4 & 4,8 & 4,0 & 3,9 \\
\hline 8 & 6,5 & 5,3 & 4,1 & 6,4 & 5,5 & 5,4 & 6,8 & 6,4 & 6,0 \\
\hline 9 & 12,0 & 11,8 & 9,3 & 11,6 & 11,1 & 10,3 & 11,3 & 10,6 & 9,7 \\
\hline 10 & 64,2 & 68,7 & 79,0 & 66,7 & 68,8 & 73,4 & 66,6 & 65,5 & 70,9 \\
\hline Total & 100,0 & 100,0 & 100,0 & 100,0 & 100,0 & 100,0 & 100,0 & 100,0 & 100,0 \\
\hline
\end{tabular}

Fonte: Elaboração do autor a partir dos microdados do Censo Demográfico 1980, 1991 e 2000/IBGE.

Obs.: Valores dos rendimentos em outubro de 2007 (INPC corrigido para o Censo Demográfico - IPEA). 
transferência de renda, intensificados ao longo da década de 1990 com foco na redução da pobreza no País.

A decomposição do índice de Gini permite mensurar a contribuição de cada fonte de renda para a desigualdade entre as rendas per capita das AMCs (Tabela 5). Caíram expressivamente as razões de concentração das aposentadorias e pensões e outras fontes entre 1980 e 2000 (25\% e $28 \%$, respectivamente) e, de maneira bem mais discreta, a do rendimento do trabalho (2,7\%). Em 1980, tanto o rendimento de aposentadorias e pensões quanto o de outras fontes contribuíam substancialmente para reforçar a desigualdade entre as AMCs, com razões de concentração, respectivamente, $20 \%$ e $56 \%$ superiores à do rendimento do trabalho. Em 2000, entretanto, a razão de concentração do rendimento de aposentadorias e pensões passou a ser $8 \%$ infe- rior ao do trabalho, e a do rendimento de outras fontes, apenas 15\% superior.

A distribuição do rendimento de outras fontes entre as AMCs merece, entretanto, estudo mais apurado sobre a diversidade de sua composição. Por exemplo, enquanto os municípios mais ricos associam-se sobretudo ao rendimento de aluguel, os municípios mais pobres associam-se aos rendimentos de programas de transferência e complementação de renda. Em 2000, 48\% dos rendimentos de outras fontes no décimo das AMCs mais ricas eram provenientes de aluguel, contra $14 \%$ no décimo mais pobre. Por outro lado, nesse mesmo ano, o rendimento de transferência de renda, como Bolsa-Família, renda mínima e segurodesemprego, representava $12 \%$ da renda de outras fontes no décimo das AMCs mais pobres, contra apenas $4 \%$ no décimo mais rico.

\section{Tabela 5_ Razões de concentração $\left(C_{f}\right)$ relativas ao coeficiente de Gini para a distribuição} da renda "per capita" entre as AMCs - Brasil 1980, 1991 e 2000

\begin{tabular}{|c|c|c|c|}
\hline Fonte & 1980 & 1991 & 2000 \\
\hline Todos os trabalhos & 0,3370 & 0,3456 & 0,3278 \\
\hline Aposentadorias e pensões & 0,4038 & 0,3665 & 0,3010 \\
\hline Outras fontes & 0,5247 & 0,4299 & 0,3759 \\
\hline Total & 0,3569 & 0,3515 & 0,3266 \\
\hline
\end{tabular}

Fonte: Elaboração do autor a partir dos microdados do Censo Demográfico 1980, 1991 e 2000/IBGE. 
A decomposição da mudança no índice de Gini entre 1980 e 2000 permite ainda identificar a contribuição de cada fonte para a redução da desigualdade entre as AMCs (Tabela 6). Nesse período, o Gini caiu de 0,3569 para 0,3266 ( $\Delta G=-0,0303$ ), e praticamente $100 \%$ dessa mudança se deveu ao efeito composição, ou seja, à redução das razões de concentração das diferentes fontes de rendimento. $\mathrm{O}$ rendimento do trabalho, embora represente quase $80 \%$ da renda per capita das AMCs, foi responsável por apenas $23 \%$ da redução do Gini dada a pequena variação de sua razão de concentração. Por outro lado, o rendimento de aposentadoria e pensões e o de outras fontes foram responsáveis, respectivamente, por $39 \%$ e $38 \%$ da redução do Gini.
Para avaliar a dinâmica espacial do grau de dependência das AMCs em relação às fontes de rendimentos, a Figura 3 apresenta a distribuição dessas segundo grupos de composição da renda total. Obtiveram-se esses grupos utilizando os valores padronizados da participação das três fontes na renda total da AMC em cada ano como critério de classificação e a técnica de $W$ ard como metodologia de agrupamento. Identificaram-se cinco grupos para representar os diferentes padrões de associação da participação das fontes nas rendas das AMCs, os quais, juntos, representavam $71 \%$ da variabilidade total observada entre as AMCs.

Embora a classificação obtida não permita quantificar as relações entre os grupos municipais brasileiros, possibilita identificar clara hierarquia nos padrões

Tabela 6_ Decomposição da mudança no índice de Gini ( $\Delta G)$ entre 1980 e 2000 para a distribuição do rendimento "per capita" entre as AMCs - Brasil 1980 e 2000 ( $\%$ da $\Delta G$ )

$(\%$ da $\Delta G)$

\begin{tabular}{l|c|c|c} 
Fonte & $\begin{array}{c}\text { Efeito } \\
\text { Composição }\end{array}$ & $\begin{array}{c}\text { Efeito } \\
\text { Concentração }\end{array}$ & Total \\
\hline Todos os trabalhos & $-1,81$ & 24,48 & 22,67 \\
\hline Aposentadorias e pensões & $-2,51$ & 41,42 & 38,90 \\
\hline Outras fontes & 4,65 & 33,77 & 38,42 \\
\hline Total & 0,33 & 99,67 & 100,00
\end{tabular}

Fonte: Elaboração do autor a partir dos microdados do Censo Demográfico 1980, 1991 e 2000/IBGE. 
Figura 3_ Distribuição espacial das AMCs segundo grupos de composição da renda total - Brasil 1980, 1991 e 2000

1980

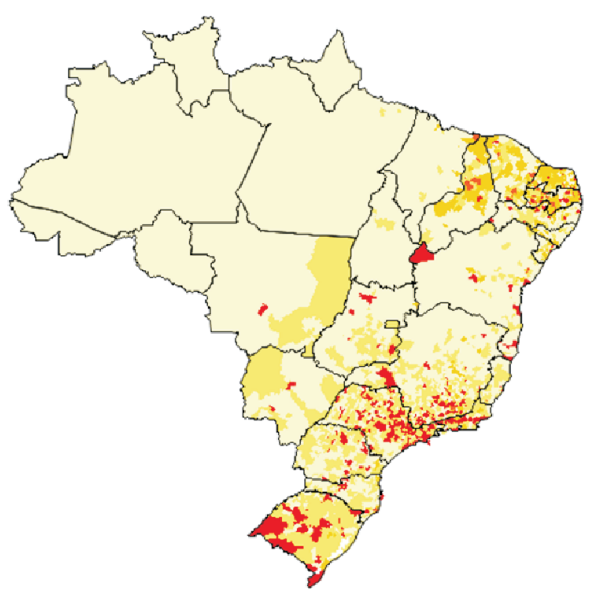

2000

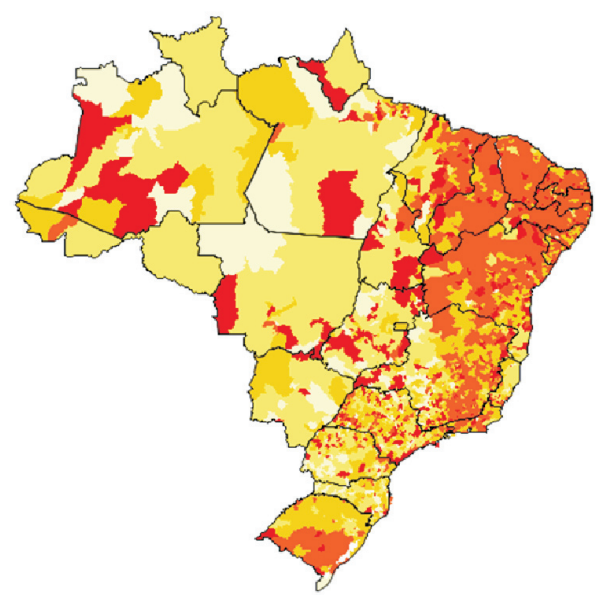

1991

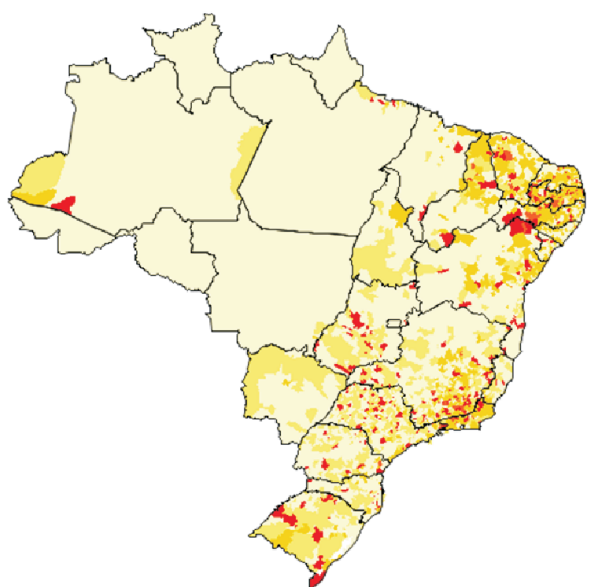

Grupo de participação na renda (percentual médio de cada fonte)

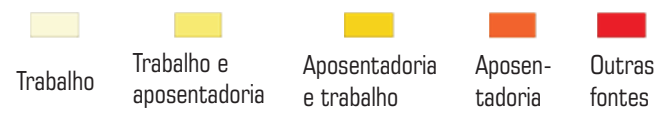

$\begin{array}{lllll}\text { Trabalho } 90,6 & 81,7 & 69,8 & 55,9 & 76,1\end{array}$

$\begin{array}{lllll}\text { Aposen- } & 6,0 & 14,1 & 24,8 & 37,2\end{array}$

Outras fontes

4,2

5,3

Fonte: Elaboração do autor a partir dos microdados do Censo Demográfico 1980, 1991 e 2000/IBGE.

Obs.: Elaborado com Cartes\&Données - Articque. 
de associação às fontes de rendimento. Do primeiro ao quarto grupo (trabalho; trabalho e aposentadoria; aposentadoria e trabalho; e aposentadoria), a tendência é a redução da participação da renda do trabalho e o aumento da participação da renda de aposentadorias e pensões. No quinto e último grupo (outras fontes), destaca-se a elevada dependência do rendimento proveniente de outras fontes. A participação média expressa na Figura 3 mostra que, do primeiro ao quarto grupo, a participação da renda do trabalho cai de $91 \%$ para $56 \%$, ao passo que a renda de aposentadorias e pensões sobe de $6 \%$ para 37\%. No último grupo, o rendimento de outras fontes representa, em média, $15 \%$ da renda total municipal, valor muito superior à média nacional em toda a série histórica.

Não houve, entre 1980 e 1991, mudanças expressivas dos padrões espaciais de dependência das diferentes fontes de rendimento. O predomínio de AMCs associadas principalmente ao rendimento do trabalho em 1980 manteve-se em 1991, com um pequeno avanço do grupo daquelas associadas tanto ao rendimento do trabalho quanto de aposentadorias e pensões, principalmente na parte oriental do território. Em 2000, entretanto, cresceu significativamente a dependên- cia do rendimento de aposentadorias e pensões em praticamente todo o território. Nesse ano, uma extensa faixa contígua de AMCs associadas, principalmente, a esse tipo de rendimento já se estendia do Estado do Rio de Janeiro à região Nordeste. Concentração também importante de AMCs associadas principalmente ao rendimento de aposentadorias e pensões aparecia no extremo meridional do Rio Grande do Sul, na mesorregião da Metade Sul.

Enquanto o envelhecimento da população e a expansão dos benefícios da previdência social ajudariam a explicar a maior dependência do rendimento de aposentadorias e pensões em quase todo o território brasileiro, dois outros fatores são fundamentais para compreender os diferentes padrões espaciais que surgem desse fenômeno: i) a dinâmica populacional; e ii) a composição dos rendimentos per capita.

No Brasil, as correntes migratórias ainda cumprem importante papel na configuração e na dinâmica da população. A região Centro-Oeste, por exemplo, assumiu papel de destaque nesse cenário a partir da inauguração de Brasília, em 1960, e na década de 70, com o êxodo de inúmeros minifundiários empobrecidos da região Sul atraídos por facilida- 
des como concessão de terras e financiamentos oficiais (Maia, 2009). Segundo Théry e Mello (2008), nos anos 1990, destacaram-se ainda fluxos migratórios centrípetos - tradicionais migrações do Nordeste e do Sul para o centro do País - e centrífugos - migrações do Sul para a Amazônia ocidental e do Nordeste para a Amazônia oriental. Como os migrantes são, em sua maioria, jovens e adultos em busca de novas oportunidades de trabalho, essa dinâmica corroborou para a maior concentração relativa de idosos nas partes menos dinâmicas do território, como nas regiões do Agreste e do Sertão nordestinos e na mesorregião da Metade Sul. Nas novas frentes pioneiras das regiões Centro-Oeste e Norte, por sua vez, há maior concentração relativa de jovens e adultos, o que condiciona a maior dependência do rendimento do trabalho.

A composição dos rendimentos per capita é outro importante condicionante do grau de dependência do rendimento de aposentadorias e pensões. Como esse depende, em grande medida, da remuneração obtida pelo beneficiário na ocupação em que se aposentou, é natural que os benefícios mais elevados localizem-se nas regiões mais desenvolvidas do território. Caso extremo ocorre no Estado do Rio de Janeiro, no qual as elevadas aposentadorias e pensões herdadas dos altos escalões do governo federal contribuem para a maior relevância dessa fonte na composição da renda estadual. Nesse Estado, o valor per capita dos rendimentos de aposentadorias e pensões era de 154 reais mensais em 2000, maior valor entre os Estados brasileiros. Essa fonte representava ainda $22 \%$ da renda total estadual. A AMC do Rio de Janeiro, por sua vez, recebia a maior parcela do rendimento de aposentadorias e pensões pagas aos municípios brasileiros (12,6\%), superior até à da capital paulista $(8,8 \%)$, que possuía população quase duas vezes superior.

Nas regiões mais pobres, por outro lado, a vinculação das aposentadorias e pensões ao piso de um salário mínimo cumpre significativo papel na composição da renda. No Nordeste, por exemplo, os baixos rendimentos per capita de aposentadorias e pensões assumem papel de destaque na renda total, graças à condição de extrema pobreza da população e aos baixos rendimentos do mercado de trabalho. $\mathrm{O}$ valor per capita médio de aposentadorias e pensões nessa região era de apenas 52 reais em 2000, mas representava, em média, $20 \%$ da renda per capita total em virtude dos também bai- 
xos valores da renda per capita do trabalho, 193 reais, e de outras fontes, 16 reais.

\section{Considerações finais}

Este trabalho propôs-se a descrever a dinâmica dos padrões espaciais de concentração de renda nos grupos municipais brasileiros entre os anos 1980 e 2000, associando-a ainda à dependência das diferentes fontes de rendimento. Explorando o uso conjunto de medidas de desigualdade, técnicas de análise de dados espaciais e de estatística multivariada, procurou-se destacar o importante papel das diferenças regionais na extrema desigualdade de renda no Brasil e a relevante contribuição dos rendimentos não provenientes do trabalho na redução da disparidade entre as rendas domiciliares per capita dos grupos municipais.

Em um primeiro momento, observou-se que a conhecida desigualdade brasileira reproduziu-se de maneira intensa na distribuição de renda entre os grupos municipais, ressaltando o importante papel das diferenças regionais no extremo grau de desigualdade da população. Poucas localidades, próximas às áreas mais desenvolvidas do território, concentravam parcela majoritária da renda nacional. A maioria dos municípios, por sua vez, é expressiva no território, mas inexpressiva na apropriação da renda.

Houve significativo crescimento da renda domiciliar per capita nacional no período de análise, sobretudo nos grupos municipais mais pobres e intermediários da distribuição de rendimentos. Essa dinâmica fez cair a desigualdade entre as localidades, embora tenha aumentado expressivamente a desigualdade dentro dos grupos municipais e a desigualdade no conjunto total da população. Não houve, entretanto, mudanças significativas nos padrões espaciais de concentração da riqueza, já que as variações mais expressivas da renda se deram próximas às áreas mais ricas do território.

Analisando a distribuição das fontes de rendimento, observou-se que a redução da desigualdade entre os grupos municipais esteve diretamente associada à maior participação do rendimento de outras fontes e, principalmente, aposentadorias e pensões na renda dos municípios mais pobres. Isso se deveu sobretudo a importantes mudanças no sistema de previdência social brasileira implementadas na Constituição de 1988, que ampliou a abrangência dos benefícios e favoreceu principalmente as populações mais pobres do País. Ademais, a vinculação do piso desses benefícios ao salário mínimo também contribuiu para a redu- 
ção da desigualdade, na medida em que esse apresentou valorização quase que contínua em termos reais a partir de 1994.

Por fim, observou-se o significativo crescimento da dependência do rendimento de aposentadorias e pensões em praticamente todo o território, especialmente em uma extensa faixa contígua de localidades que se estende do Estado do Rio de Janeiro à região Nordeste e no extremo meridional do Rio Grande do Sul. Entre os condicionantes dessa evolução, destacaram-se os baixos rendimentos do mercado de trabalho nas localidades mais pobres e a dinâmica migratória, que ainda cumpre importante papel na composição demográfica e consequentemente da estrutura de rendimentos da população brasileira. 


\section{Referências bibliográficas}

\author{
ARRIAGADA, I. Transformações \\ sociais e demográficas das \\ famílias latino-americanas. \\ In: DOMINGUES, J. M.; \\ MANEIRO, M. (Org.). \\ América Latina hoje: conceitos e \\ interpretações. Rio de Janeiro: \\ Civilização Brasileira, 2006.
}

\section{AZZONI, C. R.; MENEZES} FILHO, N.; MENEZES, T. A.; SIVEIRA NETO, R. Geography and Income convergence among Brazilian states. Research Network Working Papers, R-395, 30 p., 2000.

BAILEY, T. C.; GATRELL, A. C. Interactive spatial data analysis. Longman Scientific \& Technical, Essex, England, 1995.

BARROS, R. P.; FOGUEL, M. N.; ULYSSEA, G. (Org.). Desigualdade de renda no Brasil: uma análise da queda recente. Brasília: IPEA, v. 2, 2007.

BARROS, R. P.; HENRIQUE, R.; MENDONCA, R. A estabilidade inaceitável: desigualdade e pobreza no Brasil. In: HENRIQUE, R. (Org.). Desigualdade e pobreza no Brasil. Rio de Janeiro: IPEA, 2000. p. 21-47.
CARNEIRO, R. M. Desenvolvimento em crise: a economia brasileira no último quarto do século XX. São Paulo: Fundação da Editora UNESP (FEU), 2002. 423 p.

\section{CORSEUIL, C. H.; FOGUEL,}

M. N. Uma sugestão de deflatores para rendas obtidas a partir de algumas pesquisas domiciliares do IBGE. Rio de Janeiro: IPEA, 2002. (Texto para discussão, 897).

\section{CRIVISQUI, E. Presentación de los} métodos de clasificación. Programa Presta, ULB, 1999.

FERREIRA, A. H. B.; DINIZ, C. C. Convergência entre as rendas per capita estaduais no Brasil. Revista de Economia Política, v. 15, n. 4, p. 38-56, 1995.

FERREIRA, F. H. G.; LEITE, P. G.; LITCHFIELD, J. A.; ULYSSEA, G. Ascensão e queda da desigualdade de renda no Brasil. Econômica, Rio de Janeiro, v. 8, n. 1, p. 149-171, 2006.

FISHLOW, A. Brazilian size distribution of income. The American Economic Review. American Economic Association, v. 62 , n. 1/2, p. 391-402, 1972.

FURTADO, C. Formação econômica do Brasil. São Paulo: Companhia Editora Nacional, 1986.
HALL, R.; JONES, C. The Productivity of Nations. NBER Working Paper 5812, Cambridge, United States: National Bureau of Economic Research, 1996.

HOFFMANN, R. Transferência de renda e a redução da desigualdade no Brasil em cinco regiões entre 1997 e 2004.

Econômica, Rio de Janeiro, v. 8, n. 1, p. 55-82, 2006.

HOFFMANN, R. Distribuição da renda e crescimento econômico.

Estudos Avançados, USP - São Paulo, v. 15, n. 41, p. 67-76, 2001.

HOFFMANN, R. Distribuição de renda: medidas de desigualdade e pobreza. São Paulo: Editora da USP, 1998.

HOFFMANN, R.; DUARTE J. C. A distribuição de renda no Brasil. Revista de Administração de Empresas, Rio de Janeiro, v. 12, n. 2 , p. 46-66, 1972.

IBGE. INSTITUTO

BRASILEIRO DE GEOGRAFIA E ESTATÍSTICA. Censo

Demográfico 2000 - Documentação dos microdados da amostra. Rio de Janeiro: Fundação Instituto Brasileiro de Geografia e Estatística, 2002.

\section{IBGE. INSTITUTO}

BRASILEIRO DE GEOGRAFIA E ESTATÍSTICA. IBGE: população brasileira envelhece em ritmo acelerado. Disponível em: <http://www.ibge.gov.br/ home/presidencia/noticias/ noticia_visualiza.php?id_ noticia $=1272 \&$ id_pagina $=1>$. Acesso em: dez. 2008a.

\section{IBGE. INSTITUTO} BRASILEIRO DE GEOGRAFIA E ESTATÍSTICA. Regiões de influências das cidades. Rio de Janeiro: Fundação Instituto Brasileiro de Geografia e Estatística, 2008b.

IPEA. Disponível em: < http:// www.ipeadata.gov.br>. Acesso em: dez. 2008.

IPEADATA. Inflação medida pelo INPC. Disponível em: <http:/ / www.ipeadata.gov.br $>$. Acesso em: nov. 2008.

LANGONI, C. G. Distribuição da renda e desenvolvimento econômico do Brasil. Rio de Janeiro, Expressão e Cultura, 1973.

LEONE, E. T.; MAIA, A.; BALTAR, P. Mudanças na composição das famílias e impactos sobre a redução da pobreza no Brasil. Economia e Sociedade, v. 19, n. 1, p. 59-77, 2009. 
MAGALHAES, J. C.; MIRANDA, R. B. Evolução da desigualdade econômica e social no território brasileiro entre 1970 e 2000.

In: CARVALHO, A. X. Y.;

ALBUQUERQUE, C. W.; MOTA, J. A.; PIANCASTELI, M.

P. (Org.). Ensaios de economia regional e urbana. Brasília: IPEA, 2008. p. 135-176.

MAIA, A. G. Estrutura de classes e desigualdades. Debates contemporâneos. São Paulo: LTr, 2009.

NERI, M. Desigualdade, estabilidade e bem-estar social. Ensaios Econômicos da EPGE/FGV, n. 637, 2006.

OLIVEIRA, M. M.; MAIA, A.; BALLINI, R.; DEDECCA, C. $\mathrm{S}$. Impacto dos rendimentos de aposentadoria e pensão na redução da pobreza rural. In: CONGRESSO DA SOCIEDADE BRASILEIRA DE ECONOMIA, ADMINISTRAÇÃO E SOCIOLOGIA RURAL, 46., 2008, Rio Branco. Anais eletrônicos... Rio Branco: UFAC, 2008.

RANGEL, L. A.; ANDRADE, J.; DIVINO, J. A. Crescimento econômico e desigualdade de renda. Rio de janeiro: IPEA, 2007. ( Texto para discussão, 1312).

ROCHA, S. A investigação do rendimento na PNAD - comentários e sugestões à pesquisa nos anos 2000. Rio de Janeiro: IPEA, 2002. (Texto para Discussão, 899).

SAS. SAS/STAT - user's guide. Cary: SAS Institute Inc., 1990.
SOARES, S. S. D. Análise de bemestar e decomposição por fatores da queda de desigualdade entre 1995 e 2004. Econômica, Rio de Janeiro, v. 8, n. 1, p. 117-148, 2006. THÉRY, H.; MELLO, N. A. Atlas do Brasil: disparidades e dinâmicas do território. São Paulo: EDUSP, 2008.

UNDP. Human Development Report 2009 - Overcoming barriers: human mobility and development. United Nation Development Programme, 2009.

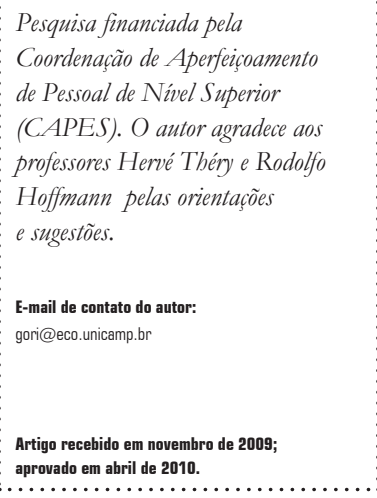

